\title{
Makna Ruwatan Wayang Cupak Dalang I Wayan Suaji
}

\author{
Made Marajaya ${ }^{1}$, Dru Hendro \\ Jurusan Pedalangan, Fakultas Seni Pertunjukan \\ Institut Seni Indonesia Denpasar \\ 1imademarajaya@yahoo.com
}

\begin{abstract}
Wayang Cupak termasuk pertunjukan langka di Bali, keberadaannya menambah genre pertunjukan Wayang Kulit Bali yang terus berkembang. Pertunjukan wayang kulit berfungsi sebagai wali, bebali, dan balihbalihan. Sebagai seni wali, pertunjukan wayang kulit hadir dalam berbagai jenis upacara termasuk upacara ruwatan. Upacara ruwatan yang paling populer di Bali disebut dengan Sapuh Leger. Selain Wayang Sapuh Leger, Wayang Cupak pun juga difungsikan untuk ruwatan seperti di Kabupaten Badung. Banyak ditemukan dalang wayang kulit di Kabupaten Badung, namun tidak banyak yang khusus mementaskan Wayang Cupak, hanya Dalang I Wayan Suaji yang merupakan keturunan dalang Wayang Cupak mampu meneruskan budaya ruwatan melalui pertunjukan Wayang Cupak. Orang-orang yang diruwat umunnya telah menginjak dewasa yang memiliki sifat loba, rakus, pemalas, dan tidak mengenal etika. Fenomena ruwatan (fenomena budaya) dikaji melalui pendekatan ilmu kajian budaya dengan metode kualitatif yang hasilnya merupakan deskripsi pencatatan hasil pengumpulan data, pengolahan data hingga analisis data tentang gejala atau fenomena yang terjadi dalam kehidupan masyarakat. Ruwatan Wayang Cupak yang terpelihara masyarakat hanya di wilayah Desa Adat Kerobokan dan sekitarnya dan sudah menjadi sebuah tradisi. Bentuk ruwatan Wayang Cupak dapat dilihat sarana dan prasarananya, seperti: canang uleman, banten ruwatan, pementasan wayang, proses ruwatan, mantra ruwatan, dan tirta ruwatan. Setelah dikaji bentuk ruwatannya, kemudian maknanya bagi masyarakat Hindu Bali. Beberapa makna ditemukan berupa: makna filosofis, makna religius, makna simbolik, makna pembersihan diri, dan makna budaya. Dapat dikatakan bahwa pertunjukan Wayang Cupak pada umumnya hanya dipentaskan untuk ruwatan dan belum disentuh oleh teknologi canggih, pertunjukannya masih sangat tradisi, dan hanya diganti gamelannya saja sebagai media untuk menciptakan iringan sesuai dengan adegan dalam lakon. Lakonnya bersumber dari cerita panji/malat atau folklore, sehingga secara filosofis wacana dikaitkan dengan konsep rwa belum ditemukan bhineda yang harus dilalui dalam kehidupan untuk menuju moksartam.
\end{abstract}

Kata Kunci: ruwatan, Wayang Cupak, Dalang I Wayan Suaji.

\section{The Meaning of Wayang Wayang Cupak Dalang I Wayan Suaji}

Wayang Cupak is a rare show in Bali, its existence adds to the growing genre of Balinese Wayang Kulit performances. The shadow puppet show functions as a guardian, bebali, and balih-balihan. As a guardian art, wayang kulit performances are present in various types of ceremonies including the ruwatan ceremony. The most popular ruwatan ceremony in Bali is called Sapuh Leger. Apart from Wayang Sapuh Leger, Wayang Cupak is also used for ruwatan like in Badung Regency. Many puppeteers are found in Badung regency, but not many specialize in performing Wayang Cupak, only the puppeteer I Wayan Suaji, who is a descendant of the Wayang Cupak puppeteer, is able to continue the culture of ruwatan through the Wayang Cupak performance. People who are being treated are generally adults who are greedy, greedy, lazy, and do not know ethics. The ruwatan phenomenon (cultural phenomenon) is studied through the approach of cultural studies with qualitative methods, the results of which are descriptions of recording the results of data collection, data processing to data analysis about symptoms or phenomena that occur in people's lives. Ruwatan Wayang Cupak that is preserved by the community is only in the area of Kerobokan Traditional Village and its surroundings and has become a tradition. The form of the Cupak Wayang ruwatan can be seen from its facilities and infrastructure, such as: canang uleman, banten ruwatan, wayang performance, ruwatan process, mantra ruwatan, and tirta ruwatan. After studying the form of the ruwatan, then its meaning for the Balinese Hindu community. Several meanings were found in the form of: philosophical meaning, religious meaning, symbolic meaning, selfcleansing meaning, and cultural meaning. It can be said that Wayang Cupak performances are generally only performed for rituals and have not been touched by sophisticated technology, the performances are still very traditional, and only replaced by the gamelan as a medium to create accompaniments according to the scenes 
in the play. The play is sourced from the panji / malat or folklore story, so that philosophically the discourse is associated with the concept of rwa and there is no bhineda that must be passed in life to get to moksartam.

\section{Keywords: ruwatan, Wayang Cupak, puppeteer I Wayan Suaji.}

Proses Review : 2 - 28 Januari 2021, Dinyatakan Lolos: 16 Februari 2021

\section{PENDAHULUAN}

Pada era globalisasi sekarang ini, pertunjukan wayang kulit tradisional mulai mengalami degradasi akibat dari perkembangan sains dan teknologi yang meng-hasilkan produk-produk hiburan baru sesuai dengan selera estetik masyarakat masa kini. Berbagai upaya telah dilakukan oleh pemerintah provinsi Bali melalui Dinas Kebudayaan untuk memertahankan dan meles-tarikan wayang yang diakui oleh UNESCO sebagai warisan budaya dunia ini agar tetap eksis seperti halnya di era tahun 1970-an hingga 1990-an, namun faktanya budaya wayang selalu kalah bersaing dengan seni pertunjukan lainnya yang menampilkan unsur-unsur estetik yang mudah ditangkap oleh penonton.

Seni dan agama khususnya di Bali tidak dapat dipisahkan seperti seni pertunjukan wayang kulit yang bersumber dari ajaran agama Hindu. Seni pertunjukan wayang kulit merupakan tradisi yang tetap dipertahan-kan sebagai pelengkap dalam suatu upacara keagama-an. Pertunjukan wayang kulit di satu sisi sebagai curahan rasa seni, dan di sisi lain untuk memenuhi rasa bakti yang mendalam demi keselamat-an umat manusia itu sendiri.

Wayang adalah simbol dari bahasa dari hidup dan kehidupan manusia dengan segala perbuatan dan dunianya. Ilmu psikologi adalah sangat relevan digu-nakan untuk membicarakan wayang dan karakter ma-nusia serta tingkah lakunya yang erat hubungannya dengan lingkungannya (Sarlito dalam Watra, 2005:3). Jadi adanya tingkah laku karena adanya motivasi, sedangan adanya motivasi karena adanya kebutuhan, adanya kebutuhan karena ada dan tidak adanya keseimbangan dalam individu (Mulyono dalam Watra, 2005:3).

Di Bali ditemukan beberapa jenis pertunjukan wayang kulit mulai dari yang klasik hingga kreasi. Adapun jenis-jenis wayang yang dimaksud antara lain: Wa-yang Ramayana, Parwa, Calonarang, Cupak, Gambuh, Arja, Tantri, dan Wayang Babad. Di antara jenis-jenis wayang tersebut di atas, ada yang hanya berfungsi untuk hiburan atau seni balih-balihan dan ada pula yang berfungsi untuk ruwatan. Jenis wayang yang berfungsi untuk ruwatan bagi umat Hindu Bali pada umumnya adalah Wayang Ramayana, Wayang Parwa, dan Wayang Cupak. Ruwatan bagi Wayang Rama-yana dan Wayang Parwa sudah umum diketahui oleh masyarakat Hindu Bali. Jenis wayang ini biasanya dipentaskan malam hari yang disebut dengan wayang peteng dan yang dipentaskan pada siang hari disebut dengan wayang lemah atau wayang gedog. Pertun-jukan wayang kulit yang khusus dipentaskan untuk meruwat orang-orang yang lahir pada wuku wayang disebut dengan pertunjukan wayang sapuh leger. Selain pertunjukan wayang kulit sapuh leger, di Bali sejak dulu kala sudah dikenal oleh masyarakat bahwa pertunjukan Wayang Cupak juga sering digunakan sebagai ruwatan. Beberapa tempat di Bali seperti; di Gianyar, Badung, Denpasar, dan Tabanan, pertunjuk-an Wayang Cupak sudah lazim dipentaskan untuk ruwatan terutama bagi orang-orang yang setelah me-nginjak dewasa dan memiliki sifat-sifat seperti yang digambarkan oleh tokoh I Gede Cupak yaitu; loba, rakus, malas, dan kesehariannya kurang beretika. Ruwatan Wayang Cupak dengan pementasan lang-sung biasanya dilakukan pada malam hari bertepatan dengan tegak otonan (hari kelahiran) seseorang, atau dapat juga dilakukan dengan hanya nunas (meminta) tirta wayang dan langsung diruwat di rumah Sang Dalang.

Menurut sejarahnya, Wayang Cupak diperkirakan muncul setelah ekspedisi Majapahit ke Bali. Sebe-lum ekspedisi Majapahit ke Bali, karakteristik agama dan budaya Hindu di Bali sangat sederhana dan lebih banyak diwarnai oleh kebudayaan dongson (pemujaan terhadap batu besar) seperti masih anismisme dan dinamisme. Setelah ekspedisi Majapahit, kehidupan agama dan seni budaya Bali mulai mengalami per-kembangan, serta mulai dikenal karya sastra dan falsa-fah-falsafah keagamaan. Kehidupan kesenian juga dikembangkan untuk menunjang perkembangan agama Hindu hingga seni pertunjukan dapat dijadikan sebagai media untuk tujuan tersebut, seperti halnya pertunjukan wayang kulit. Dengan jatuhnya Bali ke tangan Majapahit, maka raja-raja Bali selanjutnya adalah berasal dari bangsawan-bangsawan Majapahit, dan Bali mulai tunduk dan menjadi kerajaan vasalnya Majapahit. Migrasi penduduk dari Jawa ke Bali pada waktu itu secara otomatis membawa budaya Hindu Jawa, sehingga karyakarya sastra besar seperti; Ramayana, Mahabharata, Calonarang, dan cerita Malat/Panji mulai dikenal oleh orang Bali. Dengan masuknya cerita Malat/Panji ke Bali, maka dapat diperkirakan Wayang Cupak sudah ada di Bali yaitu pada zaman pertengahan atau zaman Bali Madya. Pada zaman ini wayang dijadikan untuk menanamkan nilai-nilai moral keagamaan, filsafat, etika dan semangat kepahlawanan (Seramasara, 2000:84-85).

Berdasarkan pernyataan di atas, dapat diperkirakan bahwa Wayang Cupak sudah ada sejak zaman pertengahan 
dan berfungsi untuk menguatkan upacara keagamaan khususnya ruwatan untuk menyelamatkan kehidupan manusia. Wayang Cupak sebagaisalah satu jenis wayang kreasi sumber lakonnya adalah dari Geguritan Cupak Gerantang. Geguritan Cupak Geran-tang mengisahkan kehidupan dua putra Bhatara Brahma yaitu I Gede Cupak dan I Made Gerantang yang memiliki sifat bertentangan sesuai dengan konsep rwa bhineda di Bali. Oleh karena munculnya pada abad pertengahan, maka Wayang Cupak dapat disebut sebagai wayang kreasi karena tokoh punaka-wan Merdah, Tualen, Delem, dan Sangut selalu dilibatkan dalam lakon. Pada hal keempat punakawan tersebut merupakan punakawan dari Wayang Rama-yana dan Wayang Parwa yang diperkirakan sudah terlebih dahulu sudah berkembang baik di Jawa maupun di Bali atau sekitar abad IX yang ditandai dengan ditemukannya prasasti tertua di Bali yaitu Prasasti Bebetin yang berangka tahun 818 caka atau 896 Masehi. Sementara cacatan yang paling tua yang menyebutkan adanya pertunjukan wayang di Jawa Tengah terdapat pada prasasti Jaha yang berangka tahun 762 Caka atau 840 Masehi, pada waktu itu pertunjukan wayang diberi istilah yang disebut "aringgit" (http://cakepane.blogspot.com).

Selain itu, aparatusnya juga meminjam dari pertun-jukan Wayang Ramayana seperti: kelir, blencong, dan gamelan batel. Gamelan batel biasanya dipakai me-ngiringi Wayang Ramayana merupakan bentuk pe-nyempurnaan dari gamelan gender wayang yang ditambah dengan beberapa ansamble seperti : kendang 2 buah, cengceng kecek, kajar, suling, kemong, dan kempul.

Pemberian nama pertunjukan Wayang Cupak karena berasal dari sebuah mitologi masyarakat Bali yang kini terekam dalam Geguritan (puisi) Cupak Geran-tang (Sedana, 1995:35). Dalam Majalah Wreta Citta (1996), Sedana menjelaskan bahwa telah terjadi per-ubahan peta seni pewayangan Bali pada Festival Wayang Cupak tahun 1995 yang mana sebelumnya hanya terdapat di daerah Tabanan dan Badung, tetapi kini telah muncul merata di seluruh Bali.

Wayang Cupak dengan tokoh utama I Gede Cupak dan I Made Gerantang adalah dua tokoh yang sangat berbeda baik secara fisik maupun prilaku. Secara fisik I Gede Cupak digambarkan sebagai orang yang memiliki wajah dan bentuk tubuh yang sangat buruk, sedangkan I Made Gerantang memiliki wajah dan bentuk tubuh yang sangat rupawan. Kemudian dari segi tabiat dan prilakunya juga sangat jauh berbeda. I Gede Cupak jiwa dan karakternya sangat urakan, tidak mengerti sopan santun, loba, malas, rakus, licik, dan lain-lain. Sementara I Gede Gerantang adalah anak yang sangat rajin, sopan santun, dan berbudi luhur. Kedua sifat yang berlawanan yang dimiliki oleh masing-masing tokoh di atas menggambarkan prilaku masyarakat, di Bali disebut dengan istilah rwa bhineda (Supatra, 2008:2). Pusat Dokumentasi Pro-vinsi Bali dalam bukunya berjudul "Alih Aksa Lontar Cupak" menceritakan I Gede Cupak dan I Made Gerantang berperang mengalahkan Raksasa Benaru dan I Gede Cupak dipertemukan dengan Raden Galuh. Sesungguhnya yang mengalahkan Raksasa Benaru adalah I Made Gerantang. Hal ini menunjukkan sifat kebohongan I Gede Cupak yang mengkhianati adik-nya demi seorang istri. Dalam beberapa versi cerita Wayang Cupak, kedua tokoh inilah yang menjadi idiom atau tokoh sentral dalam pertunjukan Wayang Cupak. Nilai-nilai yang terkandung dalam pertunjukan Wayang Cupak oleh masyarakat Hindu Bali telah diilhami sebagai sebuah kearifan lokal, sehingga orang-orang yang memiliki sifat dan tabiat seperti tokoh I Gede Cupak biasanya dinetralkan jiwanya melalui ruwatan Wayang Cupak.

Walaupun sudah diketahui bahwa pertunjukan Wa-yang Cupak memiliki fungsi dan makna untuk ruwatan, akan tetapi minat masyarakat untuk menjadi dalang Wayang Cupak sangatlah kecil. Tahun 1995 pertunjukan Wayang Cupak pernah dibangkitkan dan dilestarikan melalui festival oleh Pemerintah Provinsi Bali, tetapi para dalang yang ikut sebagai peserta dalam event tersebut bukanlah semuanya spesialis dalang Wayang Cupak, namun ada dalang Wayang Ramayana dan Wayang Parwa (Sedana, 1995:2).

Untuk mencari sejumlah dalang yang menekuni Wa-yang Cupak sangatlah sulit, oleh karena itu upaya festival ini dilakukan untuk mendorong para dalang untuk menjadi dalang Wayang Cupak. Di satu sisi untuk melestarikan pertunjukan Wayang Cupak sebagai seni tontonan, di sisi lain untuk menjadikan pertunjukan Wayang Cupak sebagai tuntunan bagi masyarakat khususnya yang berprilaku seperti tokoh I Gede Cupak.

Di Banjar Kancil, Desa Kerobokan Kaja, Kecamatan Kuta Utara, Kabupaten Badung, ada seorang dalang yang sangat populer dan sering melakukan pementas-an Wayang Cupak yang bernama I Wayan Warsa. Beliau lahir pada tahun 1879 dan meninggal pada tahun 1984. I Wayan Suaji memberanikan diri meke-bah (pentas perdana) pada hari Senin, tanggal 10 Oktober 1998. Pementasan yang spektakuler atau dadakan tersebut sangat mengagetkan masyarakat sekitarnya karena sudah beberapa tahun semenjak kakeknya meninggal, masyarakat tidak pernah mende-ngar berita kemunculan dalang Wayang Cupak baru di desanya. Alhasil, pementasannya sangat memuaskan penonton. Walaupun setelah pementasan itu I Wayan Suaji tidak ingat lagi tentang apa yang telah dilaku-kannya di atas pentas. Untuk selanjutnya dalang I Wayan Suaji mulai melakukan pementasan untuk kegiatan ngayah di pura-pura dan menerima pesanan pentas dari masyarakat. Hampir selama dua puluh dua tahun dalang I Wayan Suaji telah menggeluti pertun-jukan Wayang Cupak yang sebagian diantaranya dipentaskan untuk ruwatan. Fenomena inilah menarik untuk dikaji dengan pendekatan ilmu kajian budaya, sehingga diperoleh bentuk 
dan maknanya bagi masya-rakat Bali.

\section{Wayang Cupak \\ Wayang Cupak adalah termasuk wayang kulit Bali yang sangat langka. Pertunjukan ini khusus melakon-kan cerita Cupak Gerantang yang mengisahkan perja-lanan hidup dari dua putra Bhatara Brahma yang sa-ngat berbeda watak dan rupanya. I Gede Cupak di-gambarkan sebagai orang yang berwatak buruk dan memiliki rupa yang buruk pula, sedangkan I Made Geratang digambarkan sebagai orang yang berwatak baik dan disertai dengan rupa yang baik pula.}

Bentuk pertunjukan Wayang Cupak tidak jauh berbeda dengan pertunjukan wayang kulit pada umumnya yaitu memakai kelir, lampu penerangan, dan gamelan. Pertunjukan ini khusus dipentaskan pada malam hari oleh seorang dalang yang pada umumnya dijuluki sebagai dalang Wayang Cupak. Meskipun dalang-dalang pada umumnya mampu mementaskan Wayang Cupak, tetapi taksu yang dimiliki tidak sama dengan dalang turunan Wayang Cupak. Dalang turunan Wa-yang Cupak kebanyakan mementaskan Wayang Cu-pak daripada wayang lainnya. Walaupun hal itu bisa dilakukan, namun gregetnya sedikit kurang, kare-na estetika Wayang Cupak dengan wayang lainnya sa-ngat jauh berbeda. Wayang Cupak didominasi oleh tembang-tembang dengan tokohtokoh yang sangat terbatas seperti : I Gede Cupak, I Made Gerantang, Pan Bekung, Men Bekung, Raksasa Benaru, Galuh Daha, Prabu Gobagwesi, tokoh punakawan, dan tokoh bebondresan.

Pada suatu hari diceritakan Pan Bekung dan Men Bekung selalu berdoa agar mempunyai keturunan. Hal ini didengar oleh Bhatara Brahma, kemudian menge-luarkan kesaktian dan kawisesan yang berbentuk kama bang dan kama putih dalam wujud tumbuhan wong. Wong ini ditemukan oleh Pan Bekung dan Men bekung di tengah hutan, kemudian dijadikan lauk-pauk dan disantap bersama. Tidak beberapa lama men Bekung menjadi hamil. Dari buah kehamilannya, lahirlah dua orang anak yaitu I Gede Cupak dan I Made Gerantang. Dua tokoh ini merupakan simbol dari rwabhineda yaitu antara baik dan buruk, siang dan malam, panas dan dingin, dan lain sebagainya. Adapun kedua anak yang dilahirkan itu yang memiliki sifat baik adalah I Made Gerantang, sedangkan yang memiliki sifat buruk adalah I Gede Cupak. Kedua putra Bhatara Brahma ini memiliki kekuatan yang sama dan tidak bisa terpisahkan dalam kehidupan manusia. I Gede Cupak bisa masuk sorga, sedangkan I Made Gerantang tidak. Kenapa I Gede Gerantang yang selalu berbuat baik tidak bisa masuk sorga, pada hal keduanya adalah putra Bhatra Brahma?, jawaban-nya adalah orang-orang yang berwatak buruk harus diruwat oleh orang yang bersifat buruk agar menjadi baik. Bhatara Brahma melambangkan api, maka segala sesuatu akan lebur oleh api, kemudian dinetralisir dan disomiya untuk menjadi baik. Oleh karena itulah setiap orang yang lahir wajib mendapat pange-lukatan atau ruwatan Bhatara Brahma dalam upacara manusa yadnya yang pada umumnya dilakukan di dapur (tempat memasak), sedangkan bale delod dan balai dadia oleh umat Hindu di Bali dibangun dengan style Bali yaitu memiliki ruangan terbuka atau meku-pak sebagai tempat untuk melakukan upacara manusa yadnya. Setiap bangunan atapnya selalu diisi geran-tang baik dalam bentuk ikuh celedu atau simbar dan usuk atau iga-iganya disambung di bagian sisi agar atapnya lebih terangkat. Demikianlah filofofi Wayang Cupak bila dikaitkan dengan kehidupan manusia.

Perlengkapan pertunjukan Wayang Cupak hampir sama dengan pertunjukan Wayang Ramayana. Sesuai dengan perkembangan zaman, Wayang Cupak yang sedari dulunya diiringi dengan menggunakan gamelan batel, tetapi kini diganti dengan gamelan angklung atau janis gamelan lainnya. Tujuannya adalah untuk menambah dan merubah suasana pementasan yang lebih dinamis dan keratif. Pertunjukan Wayang Cupak yang berfungsi untuk ruwatan sesajen (banten-nya) lebih lengkap atau lebih besar dari pertunjukan biasa (ngayah) atau melengkapi suatu upacara tertentu. Lakon-lakon yang dapat dikembangkan pada pertun-jukan Wayang Cupak antara lain; matinya Raksasa Benaru, Cupak Dadi Ratu, Cupak Nyuti Rupa (Cupak ke Sorga), dan Cupak ke Brahma Loka.

\section{Lakon}

Lakon dalam pertunjukan Wayang Cupak memang berbeda dengan yang lainnya seperti halnya Wayang Ramayana dan Wayang Parwa. Wayang Cupak me-miliki lakon yang terbatas yang bersumber dari cerita panji. Begitu pula tokoh-tokohnya sangat terbatas. Adapun lakon Wayang Cupak yang populer hingga saat ini yaitu: Cupak ke Swarga atau ke Brahma Loka, Cupak Dadi Ratu, dan Terbunuhnya Raksasa Benaru. Bagi dalang I Wayan Suaji ketiga lakon ini sudah tidak asing baginya karena sudah semua pernah dipen-taskannya. Di era global sekarang ini, lakon dalam sebuah pertunjukan wayang kulit tidaklah memegang peranan penting seperti halnya di tahun-tahun sebe-lumnya. Alasannya, bahwa penonton milenial sekarang ini lebih menyukai pertunjukan wayang kulit model komedian. Artinya, wayang itu domainnya adalah lelucon dan unsur-unsur estetik lainnya. Hal itu sudah banyak diterapkan oleh dalang-dalang inovatif di Bali seperti dalang I Wayan Nardayana dalam Wayang Cenk Blonk-nya, I Ketut Muada dalam Wayang Joblar-nya, I Made Nuarsa dalam wayang D'Karbit-nya, dan lain sebagainya. Untuk pertunjuk-an Wayang Cupak dalang I Wayan Suaji durasi waktu untuk menampilkan punakawan dan bebondresan $40 \%$, dan untuk tokoh-tokoh sentral $60 \%$. Pertunjukan Wayang Cupak memiliki keunikan tersendiri yaitu lebih banyak mengillustrasikan tembang-tembang macepat jenis cetantungan terutama dalam angkat-angkatan atau adegan-adegan lainnya. Di samping itu, adeganadegan dalam pertunjukan Wayang Cupak juga memiliki kemiripan dengan pecalonarangan, dimana tokoh I Gede 


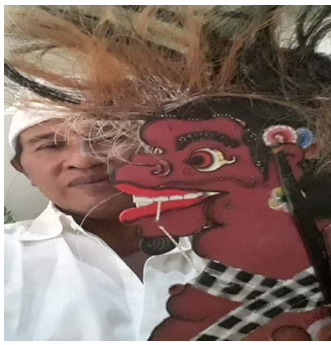

Gambar 1. Dalang I Wayan Suaji dan Tokoh dalam ruwatan (Dokumen pribadi)

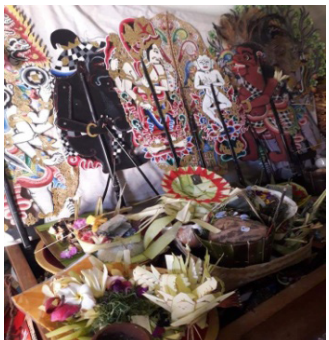

Gambar 2. Tokoh I Gede CupakWayang Cupak (Dokumen pribadi)
Cupak sebagai putra Bhatara Brahma sering mengudang para penekun desti dan ilmu hitam. Hal itu tergantung keberanian dalangnya seperti yang sering dilakukan oleh dalang I Wayan Suaji pada adegan-adegan tertentu. Walaupun dalam hati kecilnya tidak serius melakukan hal itu, tetapi sebagai daya pikat penonton terpaksa adegan ini dilakukan untuk menarik perhatian penonton.

\section{Bahasa}

Bahasa yang dipergunakan dalam pertunjukan Wa-yang Cupak adalah Bahasa Bali dan Bahasa Kawi. Bahasa Kawi hanya dipergunakan sebagai penghias untuk mematangkan lakon, sedangkan Bahasa Bali sebagai bahasa pengantar lakon. Oleh karena dalang I Wayan Suaji mempunyai pengalaman di bidang pariwisata, maka Bahasa Inggris kerap dipergunakan sebagai bahasa lelucon untuk menarik penonton. Bahasa Bali yang dipergunakan dalam Pertunjukan Wayang Cupak Dalang I Wayan Suaji adalah Bahasa Bali lumrah, dimana tokoh I Gede Cupak digambar-kan sebagai orang yang berpenampilan buruk, maka bahasanyapun menyesuaikan. Berbeda halnya dengan pertunjukan wayang kulit lainnya yang selalu mem-pergunakan sor singgih dalam adegan petangkilan, atau bila para tokoh kesatria berbicara dengan tokoh kesatria, kemudian diterjemahkan oleh punakawan dan juga untuk bahasanya sendiri biasanya digunakan berbagai tingkatan bahasa (unda usuk basa) seperti: Alus Singgih, Alus Sor, dan basa kepara. Bagi dalang I Wayan Suaji menjadi dalang Wayang Cupak tidak-lah begitu sulit, apabila seseorang mau menekuninya. Dalam pertunjukan Wayang Cupak tidak banyak ditemukan tokoh-tokoh kesatria seperti halnya dengan pertunjukan wayang kulit lainnya. Tokoh kesatria yang ditemukan dalam pertunjukan Wayang Cupak adalah Prabu Gobag Wesi. Selebihnya adalah tokoh-tokoh bebondresan yang tidak perlu menggunakan bahasa Bali Alus dan Bahasa Kawi.

\section{Penokohan}

Penokohan dalam pertunjukan Wayang Cupak tidak seperti wayang kulit pada umumnya yang ada di Bali. Pertunjukan Wayang Cupak tokoh-tokohnya sangat terbatas. Tokoh sentralnya adalah I Gede Cupak yang sekaligus merupakan tokoh antagonis, sedangkan I Made Gerantang adalah tokoh protagonis. Prabu Gobagwesi, Raksasa Detya Benaru, Raden Galuh, Pan Bekung dan
Men Bekung adalah termasuk tokoh tritagonis dan tokoh pembantu. Mengapa I Gede Cu-pak disebut sebagai tokoh antagonis, karena perilaku-nya selalu kasar, memfitnah, dan membahayakan jiwa adiknya I Made Gerantang. Berikut adalah gambar Dalang I Wayan Suaji me mperlihatkan tokoh I Gede Cupak dan wayang-wayang yang dipakai untuk Ruwatan.

Gambar 1 memperlihatkan Dalang I Wayan Suaji sedang memperlihatkan tokoh I Gede Cupak yang menjadi ikon atau tokoh sentral dalam pertun-jukan Wayang Cupak. Sementara gambar 2 adalah tokoh-tokoh wayang yang dipergunakan untuk ngeruwat. Adapun tokoh-tokoh tersebut tidak asing lagi bagi umat Hindu Bali kecuali I Gede Cupak. Adapun tokoh-tokoh tersebut adalah : I Gede Cupak, Tualen, Bhatara Ciwa/Guru, Sanghyang Acintya.

\section{Iringan}

Pertunjukan Wayang Cupak Pada umumnya diiringi dengan Gamelan Batel seperti halnya Wayang Ramayana. Bagi pertunjukan Wayang Cupak I Wayan Suaji, gamelan yang sering dipakai untuk mengiringi Wayang Cupak adalah Angklung Kebyar. Alasannya Angklung Kebyar memiliki unsur-unsur estetik yang lebih tinggi daripada gamelan Batel Wayang. Di samping itu, unsurunsur inovatif juga diperlukan untuk menambah estetika pertunjukan Wayang Kulit Cupak. Di zaman sekarang ini, sangat sulit mencari mencari penabuh Gamelan Batel dibanding penabuh Gender Wayang. Sekaa-sekaa Gamelan Batel sudah banyak yang pensiun karena hampir semua dalang-dalang di Bali tidak lagi memakai Gamelan Batel untuk mengiringi pertunjukan Wayang Kulit Ramayana. Gamelan yang dipergunakan pada umumnya yaitu: Gamelan Angklung, Gamelan Gong Kebyar, Gamelan Semarandana, Gamelan, Semarpagulingan, Gamelan Sekar Langon, dan lain sebagainya. Selain gamelan, unsurunsur estetik dari aparatus juga di-kembangkan seperti: Kelir diperlebar, lampu blencong diganti dengan lampu listrik, soundsystem dikombi-nasikan antara box speaker dengan loud speaker.

\section{BENTUK RUWATAN WAYANG CUPAK DALANG I WAYAN SUAJI}

Bentuk ruwatan Wayang Cupak Dalang I Wayan Suaji mengikuti desa kala patra atau sesuai dengan adat istiadat dan budaya masyarakat setempat. Bentuk ruwatan Wayang Cupak tidak jauh berbeda dengan bentuk ruwatan wayang kulit pada umumnya. Ruwat-an Wayang Cupak sesungguhkan hampir sama dengan ruwtan Wayang Sapuh Leger, karena sarana beban-tenan-nya berisikan guling palegembal. Sarana beban-tenan Wayang Cupak juga dapat disederhanakan sesuai dengan kemampuan dan keinginan dari si penanggap. Sarana bebantenan ruwatan Wayang Cupak ada tingkatannya. Tingkatan utama adalah ban-ten yang paling lengkap hampir sama dengan banten ruwatan Wayang Sapuh Leger. Bentuk ruwatan Wayang 
Cupak Dalang I Wayan Suaji terdiri dari canang uleman, bebantenan, ruwatan, mantra, dan tirta. Adapun bentuk ruwatan tersebut dapat diuraikan sebagai berikut.

\section{Canang Uleman Wayang Cupak}

Secara tradisi, untuk mengawali pementasan sebuah kesenian diawali dengan membawa ulemen. Ulemen adalah permohonan untuk melakukan pementasan sesuai dengan jadwal yang telah ditentukan dan disepaki bersama. Uleman disertai dengan membawa canang yang disebut uleman dengan sesari Rp. 20.000 - Rp. 50.000,. Setelah hari yang ditentukan tiba, si penanggap diwajibkan membawa bebantenan berupa perasbebakaran dan makanan tradisi upacara di Bali berupa nasi, lawar, dan sate. Uleman ini pada umum-nya berlaku jika si penanggap tinggal tidak jauh dari rumah si dalang. Bagi si penanggap yang tinggal jauh bisa sekalian membeli upakara ulemen termasuk per-lengkapannya kepada si dalang dengan/atau melalui telepon.

\section{Banten Ruwatan Wayang Cupak}

Bebantenan adalah sarana yang dipersiapkan oleh tukang banten jauh-jauh hari sebelumnya. Banten ruwatan tidak sama besarnya dengan banten mecaru, telu bulanan, metatah, potong gigi, dan perkawinan. Banten ruwatan garis besarnya terdiri dari : sorohan, daksina rong-rongan, peras bebangkit cenik, dan palegembal guling. Selain bebantenan khusus untuk ruwatan, si penanggap juga mempersiapkan banten wayang yang terdiri dari: banten pemungkah dan peras wayang.

Sebelum prosesi atau acara ruwatan dilakukan terlebih dahulu si dalang melakukan ritual ketika akan berangkat ke tempat pementasan. Ritual itu berupa ke-giatan menghaturkan sesaji peras penguleman kepada Sanghyang Pregina Taksu yang melinggih di Sang-gah Pregina Taksu. Pada saat pementasan, atau untuk mengawali pementasan Wayang Cupak, dalang I Wayan Suaji juga menghaturkan banten pamungkah. Banten ini tujuannya untuk membangunkan Sangh-yang ringgit atau Sanghyang Samirana yaitu dewanya wayang. Setelah proses ritual itu selesai dilakukan, barulah Ki dalang memulai melakukan pementasan dengan didahului membuka keropak/ gedog untuk menganbil beberapa wayang yang mulai ditancapkan di sisi samping kanan dan kiri kelir. Pada umumnya wayang yang terlebih dahulu dikeluarkan yaitu wa-yang pemurtian, wayang acintya, dan wayang kayonan. Setelah pementasan wayang selesai barulah dila-kukan prosesi pengeruwatan.

Gambar $3 \& 4$ menunjukkan model bebantenan atau sarana yang dipergunakan dalam pertunjukan Wayang Cupak. Banten di atas ada pada tingkatan madya (menengah), atau tergantung dari si tukang banten dan permintaan si penanggap. Ki Mangku Dalang akan mengikuti persediaan atau kelengkapan dari sarana-sarana dalam bebantenan tersebut berikut dengan mantra-mantranya, agar tidak

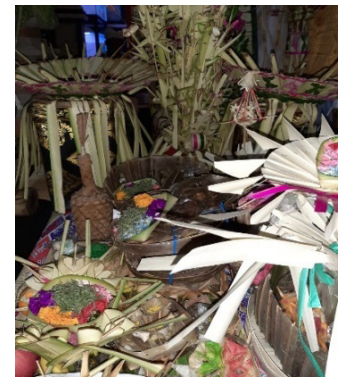

Gambar 3. Banten Ruwatan Wayang Cupak (Dokumen pribadi)

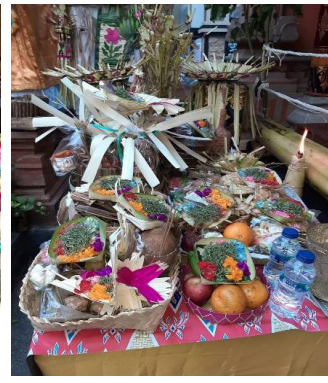

Gambar 4. Banten Ruwatan Wayang Cupak (Dokumen pribadi) lepas dari pa-ngastawa atau puja yang ditujukan kepada dewaning wayang.

\section{Ruwatan Wayang Cupak}

Aktivitas ruwatan dalam pertunjukan Wayang Cupak dilakukan setelah pementasan selesai atau hampir sama halnya dengan pertunjukan Wayang Sapuh Leger yang hanya boleh dilakukan oleh Ki Dalang. Sementara untuk pertunjukan Wayang Lemah dan lainnya ruwatan dapat dilakukan oleh Sang Sulinggih atau Pemangku yang muput (mengerjakan) suatu upacara seperti upacara Telu Bulanan (bayi berumur tiga bulan), metatah (potong gigi), dan pawiwahan (pernikahan). Prosesi ruwatan dapat dilakukan setelah banten perlengkapan terlebih dahulu dipersiapkan oleh tukang banten termasuk sarana pembuatan tirta wayang yang terdiri dari air, bunga, dupa, arak tetabuhan, canang pasucian, lis dan lain-lainnya. Selain mendapatkan percikan tirta wayang, si anak yang diruwat juga dibersihkan dengan menggunakan sarana minyak lampu blencong. Minyak lampu blencong diyakini oleh masyarakat dapat memarisuda atau da-pat menyembuhkan berbagai penyakit, maka minyak ini banyak diminta oleh masyarakat baik pada saat ruwatan itu dilakukan maupun pada besok harinya apabila masyarakat sekitar mengetahui ada peristiwa ruwatan Wayang Cupak. Berikut adalah gambar Dalang I Wayan Suaji sedang melakukan proses pangeruwatan.

Gambar 5 menunjukkan Dalang I Wayan Suaji sedang melakukan pangeruwatan /pangelukatan Wayang Cupak. Prosesi tersebut dilakukan tanpa me-lalui pementasan langsung. Hal ini dapat menghemat biaya bagi yang membutuhkan, namun tidaklah terasa lengkap tanpa paripurna ruwatan tersebut apabila tidak disertakan dengan pementasan langsung yang merupakan tradisi Hindu Bali dalam konteks ruwatan wayang.

\section{Mantra Ruwatan}

Mantra adalah kata-kata suci yang boleh diucapkan oleh sang me-ekajati (pemangku) maupun sang me-dwijati (sulinggih).Dalang termasuk golongan sang me-ekajati bukan pinandita atau sulinggih. Sang Pinandita memiliki kewenangan penuh dalam meng-gunakan mantra-mantra dan kelas mantranyapun ada tingkatannya, sehingga bisa 


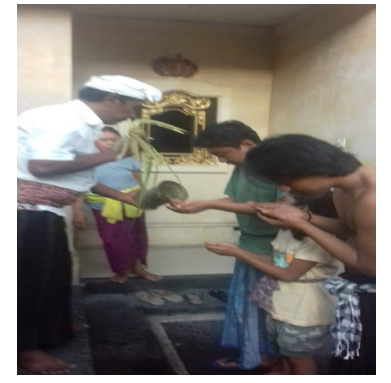

Gambar 5. Dalang I Wayan Suaji melakukan Ruwatan (Dokumen pribadi)

memuput (menyelesaikan) upacara yadnya yang besar seperti: ngaben, memukur, ngenteg linggih, mekarya, melaspas pura, mecaru rsigana, metatah, nelubulanin, pawiwahan, dan lain sebagainya. Sementara julukan pemangku (balian nyonteng) hanya bisa memuput upacara di bawah itu seperti: ngodalan tugu, otonan, ngulapan, melaspas mobil, melaspas rumah, dan lain-lain. Sang amangku dalang hanya memiliki kewenangan membuat tirta wayang dan meruwat/ngelukat seseorang. Demikian halnya dengan dalang Wayang Cupak memiliki kewenangan atau tugas utama untuk meruwat berkonsultasi dengan tukang banten. Dalam konteks ruwatan, man-tramantra yang umum dipergunakan sudah dipahami oleh seluruh dalang yang ada di Bali, kecuali dalang sendratari. Adapun mantra ruwatan Wayang Cupak yang sering dipergunakan oleh dalang I Wayan Suaji adalah sebagai berikut.

"Om suha mala mari sidhi sas sas dangku dirga yusa ya namah swaha. Om Ang Siwa pranamiya ya namah swaha. Om Ang rahpat astra ya namah swaha, Om atma tatwa atma ya nama swaha, Om kesama sampurna yan namah swaha, Om Ung sri pasupati ompat, Om sriam bawantu sukam bawantu, Om purnam bawantu, Om sidi rastu tat astu ya namah swaha, Om Ang Brahma merta sudha ya namah swaha, Om Ung merta sudha ya namah, Om Mang swara merta ya namah, Om sudha sudha sudha wari wastu yamah swaha" (wawancara tanggal, 4 Agustus 2020).

\section{Tirta Ruwatan}

Bagi masyarakat Hindu Bali istilah tirta sudah tidak asing lagi, karena setiap kegiatan upacara agama apapun bentuknya tirta selalu menjadi hal yang sangat penting sebagai sarana pemuput.Tirta adalah air suci yang telah dibersihkan dan disucikan dengan mantra-mantra. Tirta ruwatan Wayang Cupak, mantra-mantranya dipujakan atau pangastawanya ditujukan kepada Bhatara Brahma. Oleh karena itulah dalam proses pembuatan atau meraciktirta tokoh wayang I Gede Cupak didahulukan, selanjutnya diikuti tokoh Tualen, Bhatara Guru/Ciwa, dan terakhir wayang Acintya. Sebelum hal itu dilakukan yang di-ruwat terlebih dahulu di-tepung-tawari dengan sarana peras-penyeneng yang diarahkan hingga menyentuh ke dada sebanyak tiga kali, kemudian diberikan benang putih untuk diikatkan di pergelangan tangan kanan. Setelah itu barulah tirta Wayang Cupak digunakan ngeruwat dengan terlebih dahulu tirta tersebut dipercikkan ke kepala tiga kali, dipakai berkumur tiga kali dan dimi-num tiga kali. Selanjutnya tirta itu dipakai member-sihan badan jasmani seseorang dengan sarana kuskus-an (alat menanak nasi) yang disiratkan/diarah-kan ke bagian bahu/punggung atas, bagian kepala dan dada. Adapun sarana yang digunakan bernama banten lis yang dipukul-pukulkan ke punggung dan dada. Sete-lah prosesi ruwatan itu selesai barulah si anak diberi-kan tirta Bhatara Hyang Guru dan tirta-tirta lainnya yang dianggap perlu. Berikut adalah gambar proses pembuatan tirta ruwatan Wayang Cupak yang dilaku-kan oleh Dalang I Wayan Suaji.

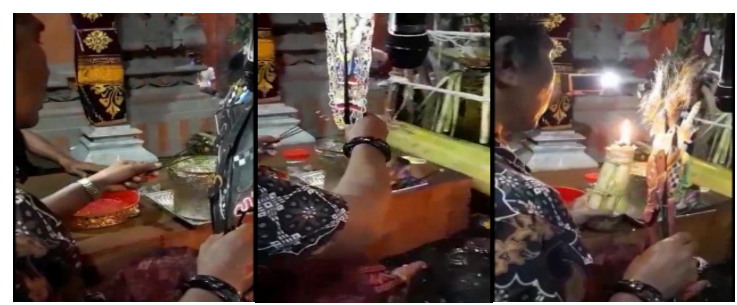

Gambar 6. Dalang I Wayan Suaji sedang membuat tirta pangeruwatan Wayang Cupak.

(Dokumen pribadi)

Gambar di atas menunjukkan Dalang I Wayan Suaji melakukan proses pembuatan tirta ruwatan Wayang Cupak, dimana tokoh I Gede Cupak diambil terlebih dahulu kemudian dilanjutkan dengan tokoh Tualen, dan Bhatara Guru/Ciwa. Sarana api yang digunakan sebagai simbol bahwa ini adalah ruwatan Wayang Cupak yang pengastawa/puja utamanya adalah dituju-kan kepada Bharata Brahma yang mampu melebur (membersihkan) sehananing seluruh) mala (kotoran) yang melekat pada badan jasmani dan jiwa rohani seseorang

Gambar di bawah ini menunjukkan bahwa setiap ruwatan apapun tokoh Acintya selalu diikutsertakan, karena merupakan perwujudan dari Ida Sanghyang Widi atau dewa yang berkedudukan paling tinggi. Dalam proses pembuatan tirta baik Wayang Cupak maupun jenis wayang lainnya, tokoh Acintya selalu dipergunakan paling akhir. Sebagai pertanda atau saksi bahwa seluruh proses pembuatan tirta wayang akan menjadi lebih sempurna dan sidhimandi.

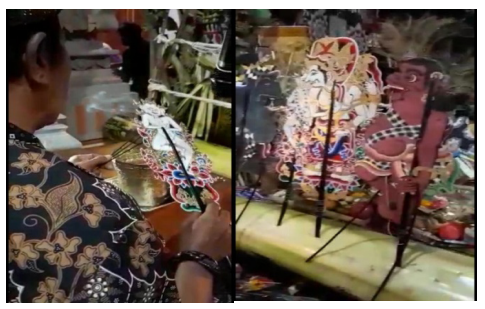

Gambar 7. Dalang I Wayan Suaji memegang Wayang Acintya dan Tokoh Wayang Untuk Ruwatan (Dokumen pribadi) 


\section{MAKNA RUWATAN WAYANG CUPAK DALANG I WAYAN SUAJI}

Ruwatan Wayang Cupak adalah bagian dari upacara keagamaan di Bali. Ruwatan Wayang Cupak dapat digolongkan ke dalam upacara manusa yadnya yaitu pembersihan diri baik secara sekala maupun niskala. Umat Hindu mempunyai keyakinan bahwa orang-orang yang mempunyai sifat buruk seperti loba, dengki, irihati, pemalas, rakus, tidak beretika, dan suka memfitnah wajib di-ruwat melalui pertunjukan Wayang Cupak. Oleh karena itulah ruwatan Wayang Cupak dipandang memiliki arti dan makna. Adapun makna ruwatan Wayang Cupak Dalang I Wayan Suaji adalah sebagai berikut.

\section{Makna Filosofis}

Pada umumnya orang yang diruwat dengan pertun-jukan Wayang Cupak bertepatan dengan hari kelahir-an atau otonan. Tujuannya untuk: (1) membersihkan pikiran supaya tidak lagi berpikir terhadap hal yang besifat buruk; (2) membersihkan mata supaya tidak lagi melihat sesuatu yang bersifat buruk; (3) member-sihkan bibir supaya tidak berkata yang kotor, memfit-nah, berbohong, menyombong kan diri, dan lain-lain ; dan (4) membersihkan hati agar memiliki perasaan dan peduli terhadap orang lain (Wawancara, tanggal, 2 Agustus 2020).

Selain itu, orang-orang yang diruwat pada umumnya setelah menginjak umur dewasa. Berbeda halnya dengan orang yang diruwat dengan Wayang Sapuh Leger yang tidak mengenal batas umur. Artinya, Begitu orang-orang mulai tumbuh dewasa barulah kelihatan prilakunya yang mengarah ke hal-hal negatif terutama orang-orang yang lahir pada hari Kajeng Keliwon. Orang-orang yang lahir pada hari Kajeng Keliwon memungkinkan menjadi orang yang sakti bisa ngeleak karena jiwanya dipengaruhi oleh Dewi Kalika atau Durga. Oleh karena itu orang-orang ini harus diruwat dengan pertunjukan Wayang Cupak yang tujuannya adalah untuk membersihkan, ngeseng (membakar) desti, membakar sifat-sifat yang buruk yang ada pada dirinya. Dalam filosofinya, api berwar-na putih untuk di jantung, api berwarna merah di hati, api berwarna kuning di ginjal, api berwarna hitam di ampru, dan api yang manca warna (brumbun) di tun-tungin hati (gantungan hati). Itulah lima jenis api yang dipergunakan untuk ngeseng (membakar) sifat-sifat manusia yang disebut dengan geni Astra (cahaya ilmu pengetahuan). Dalam perang pepelengkungan, I Gede Cupak dapat mengalahkan semua musuh-musuhnya. Begitu I Made Gerantang menantangnya untuk berpe-rang, I Gede Cupak Menyerah kalah. Artinya menga-lah demi saudara, dan merasa diri bersalah yaitu mencelakaan I Made Gerantang pada saat berperang melawan Raksasa Kala Benaru di dalam goa. Dalam perang ini I Gede Cupak diruwat oleh Bhatara Brah-ma.

Perlu dipahami bahwa I Gede Cupak dan I Made Gerantang bukanlah putra dari Bhatara Brahma. Me-lainkan Bhatara Brahma hanya memberikan panu-grahan kepada Pan Bekung dan Men Bekung berupa dua buah tumbuhan berupa wong/oong di hutan. Oleh karena men Bekung sangat tertarik dengan tumbuhan itu dan kebetulan dalam keadaan lapar, wong/oong itu kemudian dimakan oleh men Bekung. Perlu juga diketahui bahwa wong/oong itu adalah simbol dari kama bang dan kama putih. Kama bang adalah simbol ibu (pertiwi) sedangkan kama putih adalah simbol dari bapak (akasa). Kama bang dan kama putih ini ada pada diri manusia, sehingga bila ada orang yang melakukan upacara pawiwahan (pernikahan), kedua jenis kama ini dibersihkan terlebih dahulu dengan upacara yang disebut pabeyakaonan atau mekalan-kalan. Tujuannya adalah supaya si mempelai berdua kelak memiliki keturunan yang suputra. Selain itu, sarana ruwatan Wayang Cupak selalu menggunakan Babi Guling suku empat atau yang berkaki empat. Babi Guling ini dipersembahkan kepada empat sau-dara yang diajak lahir yaitu : yehnyom, getih (darah), lamad, dan ari-ari.

Dalam pengembaraannya, I Gede Cupak lalu bertemu dengan dua orang yang bertugas menjaga empelan (bendungan) yang bernama Panasati dan Tuadaya. Panasati memiliki tugas menjaga tukad (sungai). Panasati adalah orang yang bongol (tuna rungu) dan Tuadaya adalah orang yang bega (tunawicara). Kedua orang inilah yang selalu setia menemani dan menjadi punakawan I Gede Cupak kemana dirinya melangkah-kan kakinya. Arti simboliknya adalah antara panas dan dingin itu berada pada diri manusia yang disebut dengan panca mahabhuta dan tempatnya dalam pe-ngider bhuwana berseberangan yaitu panas di selatan (delod) simbolnya merah tempat Bhatara Brahma yang manifestasinya sebagai Sang Pencipta, sedangan di utara (kaja) simbolnya hitam sebagai tempat Bhatara Wisnu yang manifestasikan sebagai dewa pelindung dan pemelihara.

Selanjutnya I Gede Cupak melanjutkan pengemba-raannya sehingga sampai di kerajaan Gerobagwesi. Kerajaan ini sedang dikalahkan oleh segerombolan burung perit/ pipit dan burung geruda. Berbekal dengan akal liciknya, dalam peperangan ini I Gede Cupak dapat membunuh dan mengalahkan burung geruda dengan cara menamcapkan beberapa tombak di pinggir goa. Begitu burung geruda tewas, I Gede Cupak diberikan hadiah istri cantik oleh sang raja yang bernama Raden Galuh. Dalam kesempatan ini, I Gede Cupak menolak menikahi Raden Galuh, karena merasa diri buruk dan tidak pantas berdampingan dengan seorang istri cantik seperti halnya ketika dirinya menipu adiknya I Made Gerantang ketika melawan Raksasa Detya Kala Benaru juga dihadiahi seorang istri cantik.

Begitu menolak menikah dengan Raden Galuh, I Gede Cupak melanjutkan perjalanannya menuju Brahma Loka. Di dalam perjalanan I Gede Cupak bertemu dengan para dedemit, jin, setan, hanja-hanja, namo-namo, gregek 
tonggek yaitu iringan atau anak buah dari Durga Berawi. I Gede Cupak melanjutkan per-jalanannya sampai akhirnya tiba di marga lepas atau jalan menuju sorga yang tembus ke Brahma Loka. Pada akhirnya I Gede Cupak tiba di Prajapati yang dijaga oleh Sang Jogor Manik. I Gede Cupak mengatakan kepada Sang Jogor Manik bahwa Bhatara Brahma tidak adil menciptakan manusia, yang mana dirinya sangat buruk, sedangkan adiknya sangat rupawan. Di sanalah I Gede Cupak diberi penjelasan oleh Bhatara Brahma, bahwa I Gede Cupak bukanlah putra dari Bhatara Brahma. Bahwasannya, tidak mungkin Bhatara itu kawin/menikah dan melahirkan manusia. Ciptaan tumbuhan berupa wong/oong yang dimakan/disantap oleh Ni Ranting dan I Rantung adalah sebuah panugrahan. Oong adalah simbol dari Sang Hyang Widi. Setelah diberikan penjelasan, lalu I Gede Cupak diruwat oleh Bhatara Brahma dan seke-tika itu wajahnya menjadi tampan dan rupawan, begi-tu juga sifatnya berubah menjadi orang yang baik dan berwibawa seperti adiknya yang sejak awal sudah berwajah tampan.

Dalang I Wayan Suaji Selanjutnya mengatakan bahwa anaknya bhatara sakti yang melinggih di tua ping-gang, maka tidak boleh berbalas dendam. Bahwa adikmu itu adalah saudara yang diajak lahir bersau-dara empat yaitu: Anta, Preta, Kala, dan Bhuta Dengen. Oleh karena itu bayi yang baru berumur tiga bulan rambutnya dipetik dan sifatsifat buruknya dilebur oleh Sang Sulingih. Perlu dipahami bahwa manusia itu dilahirkan dengan cara nyolong (tidak ada tahu). Supaya tidak menjadi anak durhaka (anak bebinjat), maka dibuatkan bantencolong dengan te-busan ayam colong. Setelah anak-anak bisa mengu-capkan kata ibuk dan bapak, ke empat saudaranya yang diajak lahir berubah nama yaitu menjadi: Selahir, Jelahir, Mokahir, dan Dengen. Setelah dewasa atau akil balik, manusia itu harus dibuatkan upacara potong gigi yang tujuannya adalah untuk menghi-langkan sad ripu yang ada pada dirinya. Sad ripu adalah enam musuh yang ada pada diri manusia yaitu: kama (hawa nafsu), lobha (tamak atau rakus), kridha (marah), moha (bingung), mada (mabuk), matsarya (iri hati atau dengki). Begitu pula sudah mulai merasakan kama jaya dan kama ratih, maka ke empat saudara yang diajak lahir berubah namanya menjadi: Anggapati, Prajapati, Banaspati, Banaspati Raja. Kemudian ke empat saudara yang diajak lahir akan ikut menjaga diri kita yang bernama: Yeh Nyom menjadi Buta Jangitan, Getih menjadi Buta Langkiran, Lamad menjadi Buta Taruna, Ari-ari menjadi Buta Lembu Kama, dan diri kita sendiri menjadi Kala Dengen. Kelima saudara inilah yang biasanya diupacarai caru atau upacara mecaru oleh masyarakat Bali untuk menetralisir dan nyomia saudara-saudara kita supaya tidak lagi menganggu kehidupan kita (alam manusia) dan alam semesta (tanah yang ditempatinya sebagai tempat tinggal) (Wawancara, tanggal 15 Agustus, 2020).

\section{Makna Religius}

Kehidupan masyarakat Bali di masa silam sangat tergantung dengan alam. Perilaku mereka mencermin-kan pemikiran magis dan sakral yang kuat seperti keyakinan adanya hubungan antara manusia dengan kekuatan gaib, serta relasi antara manusia dengan kekuatan spiritual. Persepsi yang religius ini menun-jukkan sudah adanya gejala-gejala tentang keperca-yaan kepada kekuatan spiritual tertinggi atau Tuhan, yang dikondisikan oleh alam pikiran mereka memuja kekuatan alam dan alam gaib (Suartaya, dalam Suharta, 2007:60).

Dalam kitab suci dan Vedanta, ada dua pandangan yang berbeda tentang Brahman (Tuhan) yaitu sebagai yang berwujud seperti wujud para dewa (dalam Veda) dan Tuhan yang tidak terwujud seperti dijelaskan dalam kitab Vedanta (Upanisad). Berdasarkan penje-lasan dalam kitab Brahma Sutra, Tuhan Yang Maha Esa adalah yang menjadikan alam semesta dan segala yang terdapat di dalamnya (Titib dalam Sugita dan Desi Sentana, 2020 : 98-99). Memaknai teologi dalam pertunjukan Wayang Cupak, digambaran I Gede Cupak dalam perjalannya menuju Brahmaloka dengan tujuan bertemu dengan perwujudan Tuhan yaitu Bhatara Brahma.

Di kalangan masyarakat Hindu di Bali kesenian persembahan kepada Tuhan dan alam niskala dapat dibedakan menjadi dua kelompok yaitu; kesenian wali dan kesenian bebali. Kesenian wali mencakup berbagai bentuk kesenian yang tergolong tua dan oleh karena itu telah memiliki unsur-unsur keaslian (origi-nalitas) dan kesucian. Di kalangan masyarakat Bali seni sakral merupakan salah satu aspek vital kehidup-an spiritual masyarakat Hindu yang bermakna religius yang merupakan bagian itegral dari pelaksanaan upacara (Dibia, 2003:98).

Kepercayaan spiritual setiap upacara keagamaan yang dilakukan oleh umat manusia memiliki makna reli-gius, tidak terkecuali pertunjukan Wayang Cupak dalang I Wayan Suaji. Sangat jarang pertunjukan Wayang Cupak difungsikan untuk seni balih-balihan. Walaupun sudah banyak jenis wayang yang dipilih dalam ujian Tugas Akhir mahasiswa Jurusan Peda-langan Fakultas Seni Pertunjukan ISI Denpasar mulai dari ASTI hingga STSI dan terakhir ISI Denpasar, penulis belum pernah menyaksikan tontonan karya seni yang mementaskan Wayang Cupak sebagai pilihan objek penciptaan. Akan tetapi di masyarakat khususnya di wilayah Desa Adat Kerobokan, Keca-matan Kuta Utara, Kabupaten Badung, pementasan Wayang Cupak oleh dalang I Wayan Suaji kerap dilakukan untuk fungsi ruwatan. Melalui ruwatan Wayang Cupak masyarakat memaknai bahwa ada makna religius di dalamnya terbukti dengan adanya sarana banten, tirta wayang, mantra, dan lain sebagai-nya mensugestikan dan meyakinkan masyarakat akan kekuatan yang ada pada pertunjukan Wayang Cupak. Keyakinan secara niskala inilah bagi umat Hindu harus dilaksanakan melalui upacara besar dan kecil yang salah satunya adalah ruwatan Wayang Cupak. 
Mudji Sutrisna (2009:110) mengatakan bahwa seni tradisi merupakan seni rakyat yang berfungsi untuk upacara keagamaan, kesukuan, serta fungsi-fungsi lokal ritual lainnya yang sangat berlekatan dengan adat etnik religiositas masyarakat setempat. Nur Sahid (2016) juga berpendapat bahwa semiotika (ilmu ten-tang tanda) membentang di sekitar kehidupan kita, seperti pada gerak isyarat, sesaji dalam upacara, ter-masuk dalam struktur karya seni teater, sastra, film, tari, musik, dan wayang. Dalam hal ini Wayang Cupak dapat dijadikan contoh bahwa secara tradisi upacara ruwatan melalui pertunjukan Wayang Cupak sudah dilakukan secara turun-temurun oleh masya-rakat Hindu Bali dan khususnya oleh pendahulu dari dalang I Wayan Suaji. Wayang Cupak tidak saja menawarkan presentasi estetik sebagai sebuah ekspresi karya seni pedalangan, tetapi di balik itu memiliki hubungan dengan cosmologi dan mitologi yaitu hubungan antara bhuana agung dan bhuana alit.

\section{Makna Simbolik}

Falsafah wayang telah mengarungi samudra luas dari berbagai pengaruh-pengaruh luar termasuk budaya Nusantara sendiri seperti; budaya Hindu, Budha, Islam, Jawa, Sunda Bali, dan budaya Barat. Keselu-ruhannya itu telah lebur dalam bentuk wadah kesatuan arsistik yang dinamakan seni pewayangan (Wicak-sana, 1999:78). Cassirer dalam bukunya Manusia dan Kebudayaan mengatakan bahwa bentuk-bentuk sim-bolik itu adalah bahasa, mithe, seni, dan agama (Cassirer dalam Wicaksana, 1999:78). Lebih lanjut Cassirer mengatakan bahwa, tanda dan simbol masing-masing terletak pada dua bidang pembahasan yang berlainan, tanda adalah bagian dari dunia fisik, sedangkan simbol adalah bagian dari dunia makna manusiawi.

Pertunjukan wayang kulit bukan saja sekedar hiburan, tetapi juga merupakan karya seni yang mengandung filsafat yang dalam seperti yang diungkapkan oleh mangkunogoro VII bahwa: peperangan antara kesatria putih (berdarah puti) dengan raksasa dengan berbagai macam warna, pada hakikatnya bukan merupakan peperangan antara mahlukmahluk dengan segala kesaktiannya, tetapi merupakan peperangan di dalam bathin (hati) manusia itu sendiri, antara perasaan yang baik atau suci dengan yang buruk, yang selalu meng-ganggu kesadaran manusia. Suatu peperangan yang merupakan dinamika dari kehidupan manusia yang menimbulkan keindahan yang luar biasa. Menurut 'Dharma Pewayangan" seluruh perlengkapan pertun-jukan wayang memiliki makna simbolik sebagai berikut.

1. Gedebong (pohon pisang) sebagai simbul ibu pertiwi (tanah)

2. Kelir (layar) sebagai simbol kekosongan (sunya/ sunyi)

3. Blencong (lampu sumbu) sebagai simbol Dewa Surya/Matahari (bhuana agung) atau alam semesta, Jiwatma (roh) manusia atau bhuana alit. Selain itu api blencong sebagai simbol dewa agni.

4. Sanan Kropak yang diikat di atas kelir sebagai simbol langit.

5. Kropak wayang sebagai simbol alam semesta atau bhuana agung. Kalau di bhuna alit sebagai simbol perut (basang).

6. Jelujuh dan jejuluk dalam bhuana agung sebagai simbol pepohonan dan di bhuana alit sebagai simbol tulang belulang.

7. Racik sebagai simbol dalam bhuana agung simbol dari akar-akaran di bhuana alit simbol dari jari jemari.

8. Tali sebagai simbol otot/urat.

9. Dalang sebagai simbol Tuhan Yang Maha Kuasa.

10. Wayang sebagai simbol mahluk Tuhan (bhuana agung), nafsu pada manusia (bhuana alit).

11. Gender sebagai simbol irama zaman (bhuana agung) suara sukma pada manusia (bhuana alit).

12. Juru Gender sebagai sauadara empat yaitu; Anggapati yaitu yeh nyom (air ketuban) ada pada nafsu.

Mrajapati yaitu darah merah sebagai penung-gu perempatan atau kuburan

Banaspati yaitu ari-ari ada di hutan, sungai, batu besar.

Banaspati Raja yaitu klamad (lapisan kulit bayi yang tipis ada pada pohon yang besar. Itulah yang disebut saudara empat atau kanda pat sebagai benteng diri pada si dalang pada waktu mementaskan pertunjukan wayang.

13. Katengkong yaitu sebagi simbol akasa (bapak) dan bumi (ibu).

\section{Makna Pembersihan Diri}

Pembersihan diri tidak hanya dilakukan dengan cara mandi baik di rumah maupun di salon kecantikan, su-ngai, danau, maupun di laut. Masyarakat Bali pada umumnya melakukan pember-sihan diri di tempat-tempat yang disucikan. Di Bali banyak ditemukan tempat-tempat suci yang memiliki sumber air yang diyakini dapat dipergunakan untuk pembersihan diri secara niskala. Masyarakat Bali menyebut tempat tersebut sebagai tempat melukat. Hanya dengan sarana banten pejati atau canang masyarakat dapat melaku-kan pembersihan diri sesuai dengan keyakininanya. Ada tempat pemberihan diri yang dengan mengguna-kan air panas, dan ada juga yang menggunakan air dingin atau payau. Akan berbeda halnya dengan upacara pembersihan diri yang dilakukan dirumah sendiri, di rumah Sang Sulinggih, atau di purapura tertentu. Pembersihan diri secara niskala yang dilakukan di tempat-tempat tersebut di atas pada umumnya melalui bebantenan besar atau upakara kecil melalui seseorang yang sudah melalui proses upacara me-ekajati maupun me-dwijati. Proses me-ekajati dilalui oleh pemangku (balian sonteng), sedangkan proses me-dwijati dilalui oleh Sang Sulinggih/Pinandita. Selain pemangku dan Sulinggih, seniman dalangpun diberikan kewenangan untuk melakukan upacara ruwatan melalui pertunjukan 
wayang yang salah satu-nya adalah Wayang Cupak. Ada dua jenis pertunjukan wayang yang diyakini dapat diyakini untuk pemersih-an diri yaitu Wayang Cupak dan Wayang Sapuh Leger. Wayang Cupak seperti yang sudah dijelaskan pada bab terdahulu digunakan untuk meruwat orang-orang yang memiliki sifat buruk seperti tokoh I Gede Cupak yaitu suka makan, pemalas, dan memiliki akal licik dan buruk, sedangkan ruwatan sapauh leger digunakan untuk meruwat orang-orang yang lahir pada wuku wayang yang diyakini akan menjadi santapan oleh Bhatara Kala sehingga orang tersebut dalam kehidupannya ada yang sakit-sakitan, ada yang sifat-kan/wataknya keras dan berperilaku tidak seperti orang normal pada umumnya. Ruwatan melalui Wayang Cupak dapat dimaknai sebagai upacara ritual atau religius oleh masyarakat Bali dan diyakini dapat membersihkan dirinya secara niskala agar menjadi orang yang normal dan tidak berprilaku seperti tokoh I Gede Cupak.

\section{Pembersihan Jasmaniah}

Di dalam mengarungi setiap kehidupan manusia harus disertai dengan kesehatan jasmani atau fisik. Kese-hatan jasmani tentu diperoleh melalui makan yang sehat, tidur yang cukup, dan banyak berolah raga. Apabila semua kegiatan tersebut telah dilakukan dan ternyata masih ditemukan penyakit di dalam tubuh dan pengobatan secara medis belum mampu menyem-buhkan penyakit tersebut, maka satu-satunya jalan harus dilakukan melalui upacara keagamaan atau memohon secara niskala. Upacara ruwatan melalui pementasan Wayang Cupak adalah salah satu jalan keluarnya. Terbukti banyak masyarakat yang meminta dipentaskan Wayang Cupak atau cukup dengan nunas tirta tanpa pementasan pun diyakini mampu mengobati sakit jasmani seseorang. Oleh karena itulah kerap masyarakat datang ke rumah Dalang I Wayan Suaji untuk berobat dengan berbagai penyakit, dengan atau tanpa pementasan Wayang Cupak. Dalang I Wayan Cupak cukup ngastawa (memuja) kepada Dewa Brahma yang mana telah menciptakan tokoh I Gede Cupak dan I Made Gerantang untuk menetralisir sifat-sifat manusia di dunia pada (alam kenyataan) (Wawancara dengan Dalang I Wayan Suaji, tanggal 10 Juli 2020).

\section{Pembersihan Rohaniah}

Setiap orang ingin mendambakan kesehatan jasmani dan rohani. Kesehatan rohani diperoleh dengan melakukan aktivitas yang disenangi misalnya, berwi-sata ke objek wisata, menonton, melakukan tirta yatra ke tempattempat suci, melakukan upacara keaga-maan, dan lain sebagainya. Terkait dengan upacara keagamaan, dapat juga dilakukan dengan upacara ruwatan yang salah satunya adalah ruwatan Wayang Cupak. Ruwatan Wayang Cupak adalah proses penyu-cian diri atau pembersihan diri secara niskala yan diyakini dapat membersihkan jiwa rohani seseorang yang selalu diselimuti pikiran-pikiran negatif sehingga muncul prilaku yang negatif pula. Masyarakat sangat menyadari bahwa warisan leluhur berupa wayang tidak saja dimanfaatkan untuk meruwat orang yang masih hidup, melainkan dalam upacara fitra yadnya, orangorang yang telah meninggal juga sering memin-ta kepada pertisentananya untuk diruwatkan melalui pementasan wayang baik wayang peteng maupun wayang lemah. Oleh karena itulah ruwatan Wayang Cupak merupakan salah satu kegiatan religius yang dimaknai sebagai salah satu cara untuk menetralisir jiwa rohani manusia di alam nyata.

\section{Makna Budaya}

Makna budaya dapat dipahami sebagai bagian dari proses transformasi budaya secara keseluruhan yang terjadi dalam ribuan tahun, ataupun bagian yang terpenggal dan terpilah pada periode yang lebih pen-dek (Sachari, 2002:93). Hal tersebutmenunjukkanbahwasetiapaktivitasyang dilakukan oleh umat manusia secara turun temurun yang memiliki arti dan makna dapat disebut sebagai budaya. Budaya lebih bermakna perilaku sedangkan kebudayaan labih berorientasi terhadap ciptaan manusia, sehingga disebut hasil kebudayaan. Strinati Dominic (2010) menjelaskan bahwa budaya lebih berorientasi kepada aktivitas yang disukai dan disenangi misalnya budaya menonton wayang, budaya mandi ke laut, budaya berekreasi ke objek-objek wisata, budaya berolah raga dan lain sebagainya. Terkait dengan budaya berke-senian, masyarakat Hindu Bali mulai dari anak-anak sudah menyukai kesenian. Menurut Djelantik (1990). Berkesenian adalah sebuah kreativitas yang meng-hasilkan produk berupa karya seni yang mengandung keindahan. Oleh karena itu, dalam budaya berkese-nian, ada yang ingin menjadi seniman/pelaku seni atau ada yang hanya ingin menjadi penonton saja. Merujuk pada makna budaya dalam konteks ruwatan, masyarakat secara turun temurun melakukan aktivitas ruwatan melalui pementasan Wayang Cupak. Seperti halnya ketika Wayang Cupak yang dimiliki oleh Dalang I Wayan Suaji sudah beberapa tahun tidak aktif setelah kakeknya meninggal karena ketuaan, Wayang Cupak itu tidak pernah diurus oleh anak dan cucunya. Dengan kondisi seperti ini, biasanya orang-orang yang ingin melakukan ruwatan Wayang Cupak terpaksa memakai pertunjukan wayang biasa, tokoh I Gede Cupak dikeluarkan pada saat ending atau bagian akhir dari lakon atau pementasan, kemudian tokoh I Gede Cupak dipergunakan untuk meruwat orang yang memerlukan ruwatan Wayang Cupak termasuk di dalamnya tokoh Wayang Cintya, Bhatara Siwa, dan Tualen (Wawancara dengan I Made Kembar, tanggal 31 Juli 2020).

Setelah pertunjukan Wayang Cupak dibangun kem-bali, dimana dalam hal ini Dalang I Wayan Suaji bersedia menjadi dalang, maka belum waktunya atau kesiapannya untuk pentas sudah ditanggap oleh ma-syarakat yang membutuhkannya. Begitu seterusnya mulai dari mekebah tahun 1997 hingga penelitian ini dibuat. Keterangan dari fenomena ini memberikan gambaran kepada masyarakat luas bahwa masih tum-buh budaya ruwatan melalui Wayang Cupak di tengah-tengah arus globalisasi. Walaupun 
masyarakat dihadapkan dengan kemajuan zaman, namun di sisi lain justru masyarakat masih memiliki keyakinan ting-gi terhadap keberadaan Wayang Cupak yang berfungsi sebagai ruwatan.

\section{SIMPULAN}

Kesenian di Bali merupakan bagian dari agama. Kesenian selalu hadir dalam setiap kegiatan upacara panca yadnya yaitu; dewa yadnya, manusa yadnya, fitra yadnya, rsi yadnya, dan bhuta yadnya. Demikian juga halnya dengan ruwatan yang digolongkan ke dalam upacara manusa yadnya. Ruwatan dapat dilakukan dengan banyak cara yang salah satunya melalui pertunjukan Wayang Cupak. Di beberapa daerah di Bali ruwatan Wayang Cupak telah menjadi sebuah tradisi. Orang-orang yang diruwat pada umumnya memiliki sifat-sifat yang seperti digambarkan oleh tokoh I Gede Cupak. Adapun sifat-sifat buruk tersebut seperti; loba, rakus, pemalas, dan tidak mengenal etika. Ciri-ciri tersebut pada umumnya diketahui setelah orang itu menginjak dewasa. Untuk menetralisir dan mengembalikan sifat buruk itu, orang Bali meruwat nya melalui pertunjukan Wayang Cupak, bukan Wayang Sapuh Leger. Orang yang diruwat memalui Wayang Sapuh Leger adalah untuk mencari keselamatan karena dianggap lahir pada wuku yang cemer (kotor) yang diruwat dalang samirana atas anugrah Bhatara Brahma. Sebaliknya, jika orang-orang yang diruwat melalui pertunjukan Wayang Cupak bertujuan untuk membersihkan jiwa dan raga seseorang yang selalu berperilaku buruk agar kembali menjalani kehidupan yang normal atas anugrah Bhatara Brahma sebagai dewa pencipta bhuana agung dan bhuana alit. Ruwatan Wayang Cupak memakai sarana berupa bebantenan yang dilengkapi dengan : banten pengungkab, peras wayang, sorohan daksin-arongan, sodan, lis, canang pasucian, bebangkit palegembal memakai babi guling.

Setelah dilakukan ruwatan seseorang dapat melakukan aktivitasnya kembali, dan atas keyakinan seseorang yang telah diruwat menemukan jati dirinya dalam kehidupan yang normal. Oleh karena itu ruwatan Wayang Cupak memberi makna yaitu; makna filoso-fis, makna religius, makna simbolik, makna pember-sihan diri, dan makna budaya.

\section{DAFTAR RUJUKAN}

Dibia, I Wayan. 2003. "Nilai-nilai Estetika Hindu dalam Kesenian Bali”, dalam Estetika Hindu Pembangunan Bali. Denpasar : Program Magister Ilmu Agama dan Kebudayaan Universitas Hindu Indonesia Bekerjasama dengan Penerbit Widya Dharma.

Djelantik. 1990. Pengantar Dasar Ilmu Estetika Jilid I Estetika Instrumental. Denpasar. STSI Denpasar.
Muji Sutrisno dan Christ Verhaak. 2009. Estetika Filsafat Keindahan. Yogyakarta : Kanisius.

Nur Sahid. 2016. Semiotika Untuk Teater, Tari, Wayang Purwa, dan Film. Yogyakarta : Gigih Pustaka Mandiri.

Sachari, Agus. 2002. Estetika : Makna, Simbol dan Daya. Bandung : ITB.

Sedana, I Nyoman. 1995.'Festival Wayang Kulit Cupak 1995: Siasat Seniman Dalang dalam Pembinaan Seni Pewa-yangan". (Laporan Penelitian). Denpasar : STSI Denpasar.

Sedana, I Nyoman. 1996. "Festifal Wayang Cupak '95 Mengubah Peta Seni Pewayangan Bali”. Dalam Majalah Wreta Citta No. 5 Th.III Maret 1996. Denpasar : STSI Denpasar.

Seramasara, I Gusti Ngurah. 2000. "Sejarah Pewayangan di Bali : Sebuah Renungan". Dalam Jurnal Mudra Edisi No. 9 tahun VIII September 2000. Denpasar: STSI Denpasar.

Suartaya, Kadek. 2001. "Transformasi Cak dari Ritus Magis Ke Presentasi Estetis". Tesis. Program Pascasarjana Universitas Udayana.

Sugita I Wayan dan Desi Sentana. 2020. Ajaran Kanda Pat Dalam Wayang Cupak. .Denpasar : Paramita.

Supatra, I Nyoman Kanduk. 2008. Cupak ke Brahmaloka. Denpasar : Pustaka Bali Post.

Watra, W. 2005. Filsafat Wayang dalam Panca Yadnya. Surabaya : Paramita.

Wicaksana, I Dewa Ketut. 1999. "Wayang Sapuh Leger Fungsi dan Maknanya dalam Masyarakat Bali”. Jurnal Mudra No. 6 Tahun VI Maret 1998. Denpasar: STSI Denpasar.

Sumber Lain:

http://cakepane.blogspot.com.

Nara Sumber :

I Wayan Suaji, tempat/lahir : di Banjar Kancil 1962, pekerjaan : seniman dalang, Alamat : Banjar Kancil, Desa Kerobokan Kaja, Kecamatan Kuta Utara, Kabupaten Badung. 